\title{
Natriuretic Peptides A
}

National Cancer Institute

\section{Source}

National Cancer Institute. Natriuretic Peptides A. NCI Thesaurus. Code C139910.

Natriuretic peptides A (153 aa, $\sim 17 \mathrm{kDa}$ ) is encoded by the human NPPA gene. This protein is involved in uterine artery remodeling, trophoblast invasion, natriuresis, diuresis, and vasodilation. 